\title{
BLOOD TRANSFUSION IN WAR *
}

\author{
Major-General H. .C. JEFFREY, \\ Q.H.S., M.D., F.R.C.P.(Ed.)., F.R.C.Path., D.T.M.\&H.
}

Director of Army Pathology

THE major factors influencing the organization of blood transfusion services in war are:-

(a) Appreciation of the indications for blood transfusion in this context,

(b) Study of the likely environment in which the service will operate,

(c) Consideration of the availability of personnel, blood and equipment.

\section{Indications for blood transfusion}

\section{Historical background}

There are many historical allusions to blood transfusion, but until Landsteiner's work on the ABO groups at the beginning of this century (Landsteiner, 1901) and the development of anticoagulant solutions during the First World War, there was no scientific basis for the use of blood for transfusion. Indeed, the earlier references to transfusion did not consider the main value of this procedure, replacement therapy.

The geriatrician may be interested in the views of one Andreas Libavius who suggested in 1615 that an old man's weakness could be dispelled by transfusion of the "hot and spirituous blood" from a young man.

The venereologist may find a new approach from Denis who recorded in 1667 the transfusion of a man who was suffering from a "Phrensy", which, he judged, "was occasioned by a disgrace he received a little before in some Amours".

The psychiatrist can find a number of references to attempts to treat patients suffering from mental illness by transfusion, such as that of Lower who in 1667 transfused a man " that is a little frantic". The experiment, with lamb's blood, proceeded without mishap and afterwards the patient stated that he felt a little better, although Pepys, who recorded this incident, observed that " he is cracked a little in the head".

The ordinary clinician, however, has to wait until early in the 19 th century for the first glimpse of the rational use of transfusion. In 1825 Doubleday described in the Lancet the transfusion of a woman suffering from post-partum haemorrhage. $\mathrm{He}$ recorded that "her life was in imminent danger, and in fact from all the symptoms there was no probability that she would live more than three or four hours ". After receiving some 6 ounces of blood, the patient, previously semi-comatose, suddenly exclaimed "By Jeasus, I feel as strong as a bull".

A few years later Blundell (1828) described a transfusion given in similar circumstances. The patient was in " an alarming state of collapse ", but brandy and port wine, freely given, had little effect. After the transfusion the patient said that she felt " as if life were infused into her body".

* A paper presented at the D.M.S., B.A.O.R. Study Period, November, 1972. 


\section{Indications for transfusion}

So that the rational use of transfusion is replacement therapy. It has been argued by Crosby (1964), a- transfusion expert in the United States, that there will be no place for blood transfusion in the mass casualty situation arising in thermonuclear war. To accept this would make my task very easy-I could sit down again-but though it might sound very elementary we must have a clear view of the indications for blood transfusion in such a situation, where we may be faced with casualties from the triple hazards of trauma, burns and radiation.

Trauma. In the early stages of injury, oligaemic shock is the danger. A sudden loss of 30 per cent of the circulating blood volume is serious. When greater amounts are lost there is severe circulatory collapse, blood pressure is no longer maintained and the supply of oxygen to vital centres is no longer adequate. A sudden haemorrhage of 2 litres, that is some 50 per cent of the average blood volume, is probably always fatal if left untreated. On the other hand, a loss of 30 per cent of red cells is not of major consequence in a previously fit man and a 50 per cent loss can be well sustained. So that the imperative demand in the initial treatment of oligaemic shock is the restoration of blood volume-and that can be done without red cells. Once the blood volume has been restored with a fluid other than whole blood, however, and the danger of circulatory collapse averted, then the resultant acute anaemia may seriously interfere with oxygen carrying capacity. Further loss of red cells at operation may then be lethal. It is at this stage, when the patient comes to surgery, that whole blood or red cells may be essential to life. It has been estimated that of the 12 per cent of wounded in World War II requiring transfusion, some half would have died if facilities for blood had not been supplied. Such figures make nonsense of the statement one so often hears that blood transfusion in forward areas in war will be a " bonus". If some 6 per cent of casualties die without it, it cannot be a bonus to supply blood, but a tragedy if we cannot.

As whole blood or red cells for traumatic cases are an adjuvant to surgery, it should be available at first surgical team level, that is with field hospitals as well as throughout the evacuation chain to the rear of this.

Burns. There may be local destruction of red cells in deep burns, probably seldom more than 12 per cent, but in the early stages the serous exudate over the burnt area and oedema of surrounding tissues produces a combination of oligaemic shock and dehydration, the red cells being mainly left intact, so that the blood thickens. In the initial stages, at least, there is no requirement for blood. Later on there may be interference with normal red cell production and then whole blood or red cell transfusion may be indicated but, except in very deep, extensive burns, red cells are not required for some days.

Depending on the success of evacuation, the main site of requirement of blood transfusion for burns may be at general hospital level.

Radiation. In those receiving median doses of radiation, in the 300 to $600 \mathrm{rad}$ region, the main affect is on the bone marrow with stem cell necrosis. This is reflected in the peripheral blood after a period bearing a relationship to the normal life span of mature blood cells so that after initial nausea and vomiting the patient is relatively free from symptoms for a period of some three weeks. The only treatment possible at present for the bone marrow syndrome is supportive, which includes blood transfusion, 
until regeneration has occurred, but the requirement will not be for some weeks after a nuclear exchange.

\section{Summary of indications for transfusion}

Blood should be available at field surgical team level as an adjunct to surgery for traumatic cases; the requirement for the treatment of burns is not so pressing and may be principally at general hospital level. Radiation casualties will not require transfusion for some weeks after exposure.

\section{The battlefield environment in relation to the provision of blood}

The first time that blood transfusion was recorded in military operations appears to have been during the American Civil War of 1864-65; it was carried out to a certain extent during the First World War, but it was not until Loutit and Mollison's (1943) work on acid-citrate-dextrose as an anticoagulant that blood transfusion really came into its own. This enabled the widespread use of stored blood and throughout the Second World War the demand for blood increased steadily from a figure of some 400 pints used during the short Dunkirk operations of 1940 to some 100,000 pints transfused during the campaigns of the British Liberation Army from June 1944 to May 1945.

During the war an adequate transfusion service in the field was possible by the supply of blood from the United Kingdom (U.K.) or base areas with a field organisation, the Base Transfusion Unit, designed for the storage and forward distribution of blood in refrigeration vehicles and containers.

If there is a major conflict in the future, it may be heralded by a few days of conventional warfare then a sharp, short period of nuclear exchange, or nuclear weapons may be used from the outset. Any planning must be based on the worst possible situation which in this case could be a period of nuclear chaos. Three major points arise from this:

(a) That movement will not be freely possible so that many areas, and in nuclear war this means the rear as well as forward, may be in a state of LOGISTIC ISOLATION.

(b) That all parts of a force will be at risk so that DISPERSAL OF RESOURCES is vital.

(b) That the principal weight of attack may not be foreseeable so that FLEXIBILITY is essential.

These three factors: Logistic isolation, Dispersal of resources and Flexibility in organisation, must be borne in mind constantly.

In the context of the supply of blood in these circumstances the following points must be taken into consideration. It may well be that heavy nuclear or high explosive sorties will be directed against the United Kingdom, the collecting and sending organisation at home may well be disrupted, air transport may not be available. The demand for blood for civilian casualties may well be much greater than that for the Army in the field. External sources of blood supply cannot be relied upon. This means local availability in the theatre of operations.

Even if collecting sections of a blood supply unit could fill mobile base blood banks from donors in the rear, disruption of lines of communication may make distribution of blood by road impossible-remember the factor of logistic isolation-and airlift can never be certain. Base blood banks of this nature would also be vulnerable-the principle of dispersion is ignored. 
So I think it follows inevitably that a realistic assessment of the problem of blood supply in nuclear war must accept the possibility, indeed the probability, that if blood is not available with potential user units, there will be no blood available at all.

This is the fundamental thesis on which I have based my concept of the transfusion service in war.

\section{Consideration of the availability of personnel, blood and equipment}

To recapitulate so far, blood should be available as an adjunct to surgery at first surgical team level as well as throughout the evacuation chain for traumatic cases; the greatest demand will be in the early phases of the battle. Depending on evacuation, the requirements for burns cases will be further to the rear, the main demands being a few days after the infliction of these injuries; radiation casualties will not require blood for some weeks by which time active operations are likely to have ceased and the rehabilitation phase in being. Within this time scale, how can blood be made available with user units?

To enable flexibility to meet changing situations I think this problem is best met by a dual, complementary system; facilities for local donation and stockpiles of frozen blood. I do not think that either of these alone would meet the situation. Pre stockpile of frozen blood should enable large quantities to be immediately available, but such banks are immobile and vulnerable and there is a limitation to their size; once the blood is used replenishment of the banks would not be feasible on any large scale in the environment of the nuclear aftermath. Facilities for local donation give flexibility and a long term potential, but might well fail to meet initial requirements, a point I will elaborate shortly.

Local procurement of blood. Local procurement of blood requires consideration of technical procedures necessary to ensure that transfusion are safe, the source of donors and personnel and equipment required.

Technical procedures. Meticulous laboratory control will often be impracticable in forward areas under the stress of a mass casualty situation. The only way to ensure relative safety of transfusion in such a situation is to pre-group all troops by accurate laboratory procedures and record the group on the man's identity disc so that homologous blood, that is blood of the same group, can be taken and given if necessary without further check. This universal grouping is now carried out for both the Regular and Reserve Army.

There are a number of possible sources of donors, such as disengaged troops, the lightly wounded in this context and cadavers. In the initial stages, at least, of modern war the number of disengaged troops may well be minimal; those who escape incapacitating injury will be expected to fight and non-combatant troops will be working round the clock to restore some semblance of order; this lack of potential donors is the main reason why we cannot rely solely on local procurement of blood for early casualties. As a last resort the lightly wounded man would appear to be a possible source of blood. While it would appear morally indefensible to take blood from a man requiring medical attention, one could envisage a different attitude in nuclear chaos. The average haemoglobin content of men in the army is about $15 \mathrm{~g}$ per $100 \mathrm{ml}$. Under peacetime conditions the Army Transfusion Service requires a level of $13.5 \mathrm{~g}$ before a donor is bled, civilian practice generally takes $12.5 \mathrm{~g}$ as an acceptable level. The lightly wounded man who is 
incapacitated in such a way that he cannot fight, who will be in the evacuation line and who has lost a pint of blood, equivalent to $1.5 \mathrm{~g}$ of haemoglobin per $100 \mathrm{ml}$, will not be jeopardised by the donation of one pint of blood.

The use of cadaver blood appears on the surface to be a reasonable expedient; it plays a part in normal Russian transfusion practice. Blood coagulates after death, but after 1 to 2 hours fibrinolysis sets in and the blood re-liquifies and can be removed. After a further 6 hours or so cell deterioration sets in, so that there is only a brief period when cadavers could be bled. Quite apart from this limitation, however, most of the dead on the battlefield will have been injured and there would be a high risk of infection; this is the greatest drawback to the use of cadaver blood. Such limited effort that is available should be devoted to trying to collect the living rather than the dead.

Personnel and equipment. The present establishment of a Blood Supply Unit was designed to meet the factors influencing medical planning mentioned earlierlogistic isolation, dispersion and flexibility. It consists of a number of mobile bleeding teams which can be dispersed with potential user units when hostilities appear imminent. Should there be logistic isolation, such units have local procurement facilities; if and when movement is permitted, teams can be dispersed or aggregated accordingly to local needs. Such an organisation can cope, not only for the worst possible situation, but for the demands in conventional warfare. Plastic transfusion equipment presents no logistic problems and with refrigerators in units having a surgical capacity, bleeding teams could operate within the limits of available donors. This, I think, is a realistic approach; forces in the battlefield can always have some sort of blood transfusion service.

\section{Stockpiling of frozen blood}

Although requirements of blood in a mass casualty situation may not be as vast as some people have envisaged, local procurement of blood is unlikely to provide sufficient in the early phases of a war when, as I have indicated, few troops will be disengaged and available as donors; a stockpile of blood would meet this initial requirement.

As you know, red cells preserved in acid-citrate-dextrose solution and stored at a temperature of 4 to $6^{\circ} \mathrm{C}$ have a life span of some 21 days; even the addition of adenine which increases the storage life to some 6 weeks would not enable a stockpile of blood to be maintained.

Much work has been done in the past 12 years or so on the long term storage of blood - in terms of years - by freezing. The problem in freezing blood is the prevention of haemolysis. Blood will freeze at a temperature of minus 2 to minus 3 degrees centigrade, but the ice crystals which form cause almost total destruction by a combination of mechanical damage and increased salt concentration.

There are two main approaches to this problem. The first is to add what is literally a large quantity of anti-freeze to the cells so that water in them is bound and not available for ice crystal formation. In practice this is achieved by adding glycerol as an intracellular cryoprotective agent. As red cells thus treated haemolyse in vivo, removal of the glycerol is required before they are transfused and hence a post-thaw process is mandatory.

The second approach is to freeze the blood so quickly that ice crystals have no time to develop. This can be achieved by adding an extracellular cryprotective agent such as hydroxyethyl starch (HES) and freezing over a few seconds in liquid nitrogen. 
The criteria for the preservation of red cells for military use may be summarised as:-(a) The product must be therapeutically effective and clinically acceptable. (b) It must have a long life. (c) Ideally there should be no requirement for a post-thaw process. (d) Maintenance of the frozen state during prolonged storage must be assured.

How do present techniques measure up to these criteria? Numerous processes have been described, but many of these differ only in minor processing techniques and basically there are three lines of approach to freezing blood, all of which have been investigated by the R.A.M.C. over the past 12 years:-

(a) The use of glycerol in high concentration as an intracellular additive with freezing and storage in a mechanical refrigerator at minus $80^{\circ} \mathrm{C}$.

(b) The use of glycerol in low concentration as an intracellular additive with freezing in liquid nitrogen and storage in the gas phase of liquid nitrogen at minus $150^{\circ} \mathrm{C}$.

(c) The use of an extracellular additive such as HES with again freezing in liquid nitrogen and storage in the gas phase of liquid nitrogen.

The high glycerol process has been developed particularly by Huggins (1966) in Boston, United States of America (U.S.A.). This produces a product which is clinically most satisfactory and has been widely used in the U.S.A. and a number of other countries. While this is a most valuable method for peacetime use, there is doubt as to whether blood stored by this method has a life of over two years (Valeri and Rienck 1969) and the post-thaw process requires time, technical skill, complex equipment and about 4 litres of wash fluid per unit of blood, so that there are serious logistic drawbacks to its use in the field. As storage is in a mechanical refrigerator, breakdown or interruption of electricity supplies might jeopardise a stockpile.

The low glycerol process in liquid nitrogen is associated particularly with the names of Krijnen (Krijnen et al 1964) in Holland and Rowe (Rowe, Eyster and Kellner 1968) in the U.S.A. It produces a highly acceptable product clinically and the frozen blood may well last indefinitely. Storage in liquid nitrogen refrigerators means that the stockpile is independent of mechanical and electrical failures. The post-thaw process is still complicated and a logistic problem, but is simpler than the Huggin's process.

Processes using an extracellular additive and liquid nitrogen freezing have been investigated mainly by Knorrp and his colleagues (1967) in the U.S.A. and Whitcher (1964) and Robson (1969) in the U.K. High hopes were entertained that this method would lead to a one-stage approach which would give a product which would not require any post-thaw processing, but this ideal has not yet been reached. Although such additives as HES, in contradistinction to glycerol, need not be removed, on thawing the blood contains an unacceptable amount of free haemoglobin. One serious drawback to the development of this method is the short supply of HES, but it is hoped that this will be overcome and a simple post-thaw process, designed to remove the supernant haemoglobin, evolved. As in the Krijnen process, stockpiling by this technique in liquid nitrogen refrigerators would be independent of mechanical or electrical failure.

In the present state of knowledge, then, the low glycerol technique with freezing and storage in liquid nitrogen is the method of choice for stockpiling blood for war. If, in the future, the HES method permits the recovery of an acceptable product with a simpler post-thaw process, it would be simple to change over to this technique as the 
hardware is the same. At present the Army Blood Supply Depot are investigating the properties of HES of different polymer constituents made in the U.K.; looking into the post-thaw survival time of the product; assessing the optimum fluid for suspension of the thawed cells and trying out plastic containers for freezing and storing blood.

While the primary aim of the Army work is to stockpile blood for use in war, a secondary aim, to enable frozen blood to be used for routine peacetime requirements, has much to commend it because:-

(a) It enables seasonal variations in donor response to be levelled out.

(b) It stresses the concept of component therapy which should be the ultimate aim in a transfusion service, that is, if a patient requires red cells he is given just those and not a mixture containing platelets, effete white cells and possibly hepatitis virus.

(c) Because of this component therapy approach, reactions occurring in patients requiring repeated transfusions are reduced.

(d) A bank of rare bloods may be maintained.

(e) Peacetime experience is gained for wartime practice.

Stockpiling of frozen blood for the Army in B.A.O.R. is no longer theoretical. An initial storage point has been established at Munster consisting of, at present, 5 liquid nitrogen refrigerators, total capacity 1,000 units of blood and these are now nearly full. This storage point will be extended to 15 refrigerators this year and thereafter further storage points will be established.

It is hoped that this blood will be used in part for peacetime requirements so that medical officers will obtain confidence in the use of frozen blood, laboratory staffs will ob:ain experience in technical aspects and stocks can be turned over.

To stress the point that blood transfusion is just as important in war as in peacetime practice, I will end by reading part of a letter sent home in January 1941 by a soldier wounded at Jibuti, in the former British Somaliland: "I was given a blood transfusion. I thought it one of my most wonderful experiences of the war. You watch the liquid slowly descending in the glass and every second you feel stronger as if you were being drawn up from a pit by some invisible hand. The fog of weakness rolls away and you stagger out into the sunlight again".

\section{REFERENCES}

BLUNDELL, J. (1828). Lancet i, 431.

Brown, H. M. (1917). Ann. med. Hist. 1, 177.

CrosbY, W. H. (1964). Ann. N.Y. Acad. Sci. 115, 399.

DENIS, J. (1667). Phil. Trans. Roy. med.-chir. Soc. 2, 618.

DOUBLEDAY, D. (1825). Lancet, ix, 111.

HugGins, C. E. (1966). Monogr. surg. Sci. 3, 133.

Knorpp, C. T., Merchant, W. R., Gikas, P. W., SPencer, H. H. and Thompson, N. W. (1957). Science 137, 1312 .

Krijnen, H. W., DeWit, J. J. F. M., Kuivenhoven, A. C. J. and Vander Reyden, G. (1964). Proc. 10th Congr. Intern. Soc. Blood Transfusion. Stockholm. P. 683.

LANDSTEINER, K. (1901). Wien. klin. Wschr. 14, 1132.

Libavius, A. (1615). Cited by Brown (1917).

Loutit, J. F. and Mollison, P. L. (1943). Brit. med. J. ii, 658.

LOWER, R. (1667). Cited by Brown (1917).

Robson, D. C. (1969). Proc. Intern. Symposium on Modern Problems of Blood Preservation. Frankfurt.

ROWE, A. W., EYSTER, E. and Kellner, A. (1968). Crybiology 5, 119.

VALERI, C. R. and RIENCK, A. H. (1969). Transfusion 9, 5.

Whitcher, H. W. (1964). Proc. roy. Soc. Med. 57, 631. 